\title{
The role of associative strategies in the acquisition of P-A material: An alternate approach to meaningfulness ${ }^{1,2}$
}

\author{
CLESSEN J. MARTIN AND DAVID L. COX, MICHIGAN STATE UNIVERSITY \\ FREDERICK J, BOERSMA, UNIVERSITY OF ALBERTA, EDMONTON
}

\begin{abstract}
Abstraet
This study examined the effects of stimulus and response $\mathrm{M}$ on paired-associate learning when responses were equally available. A recognition procedure was used for equating response availability. The findings concerning relative performance on the four lists and the greater influence of $M$ on the response side are consistent with previous studies. Associative strategies employed by Ss during the learning task were also collected and analyzed. Contrary to the acquisition data, the strategy data revealed that $M$ exerts a greater effect on the stimulus side. The results were discussed in terms of Underwood and Schulz's two-stage of associative learning.
\end{abstract}

\section{Problem}

Studies in verbal learning reveal that performance on paired-associate tasks is a function of the meaningfulness $(M)$ of the stimulus and response, and that variations in $M$ on the response side have a greater affect on rate of acquisition than do those on the stimulus side (e.g., Cieutat, Stockwell, \& Noble, 1956)。 Underwood \& Schulz (1960, pp. 84-127) state: "Without exception, all definitions of $\mathrm{M}$ can be translated into frequency terms," and "... that the frequency with which verbal units have been experienced directly determines their availability as responses in new association connections." In addition, they postulate that verbal learning occurs in two stages, namely, a response-learning stage and an association-hook-up stage. More specifically, Underwood and Schulz posit that variation in $\mathrm{M}$ on the response side has its primary effect upon response availability. If the problem of availability were eliminated, the effect due to variation in $M$ on the response side should be minimized.

Epstein (1963) attempted to eliminate differences in response availability by having Ss learn the response items to a criterion of complete free recall before presenting them with the paired-associate task. Because his results did not support Underwood and Schulz's interpretation of $M$ with respect to response availability, he suggested that his procedure might not have eliminated differences in response availability. It is possible, however, that factors other than just availability are associated with differences in the $M$ value of the response. For example, the types of cues employed by Ss may be different when there are variations in $M$ on either, or both, the stimulus and response $\operatorname{side}(\mathrm{s})$.

One purpose of the present study was to make all responses equally available by using recognition method instead of the traditional anticipation method. This procedure should eliminate response learning and guarantee availability of response items regardless of $M$ values. A second purpose was to study verbal reports obtainea from Ss. Such information might provide valuable data concerning the types of cues (strategies) employed by Ss in learning paired-associates at different $\mathrm{M}$ levels. In addition, this data might suggest an alternative approach to the study of meaningfulness.

\section{Material}

Sixteen low (L) and 16 high (H) items were selected from Noble's (1952) list. The mean values for the $L$ and $H M$ items were 1.31 and 7.54 respectively. Four lists of eight pairs each were formed from these items. The $L_{1}-L_{2}$ list consisted of pairs combined from $L M$ items-the mean difference in $M$ between the stimulus and response sides was .005 . List $\mathrm{L}_{1}-\mathrm{H}_{2}$ contained the same stimuli paired with $\mathrm{H} M$ responses-the mean difference in $M$ between the stimulus and responses for this list waw 6.18. The $\mathrm{H}_{1}-\mathrm{L}_{2}$ list contained the responses used in the $\mathrm{L}_{1}-\mathrm{L}_{2}$ list paired with $\mathrm{H} M$ stimuli. The mean difference in $M$ between the stimulus and response sides for these items was 6.29. List $\mathrm{H}_{1}-\mathrm{H}_{2}$ comprised the stimuli used in the $\mathrm{H}_{1}-\mathrm{L}_{2}$ list paired with the other $8 \mathrm{H} \mathrm{M}$ items. The mean difference in $\mathrm{M}$ between the stimulus and response sides here was .12.

\section{Subjects}

One-hundred and sixty Michigan State University undergraduates, 92 males and 68 females, served as Ss for this study. A group testing procedure was used and each group was randomly assigned to one of the four list conditions. Since classes were of unequal size, Ss were randomly eliminated so that each grcup contained $40 \mathrm{Ss}$.

\section{Proeedure}

The items were placed on Thermofax transparencies and presented on an overhead projector in different random orders, for both learning and test trials. Ten learning and 10 test trials were presented alternately. A 3 sec. presentation rate was used for learning trials, and a $4 \mathrm{sec}$. rate for test trials. A recognition procedure was employed for test trials with each stimulus being paired with all eight responses. The responses on the test transparencies were randomized to avoid any serial position effect. Ss were provided with test booklets to record their answers. At the conclusion of the learning task each pair was presented for $60 \mathrm{sec}$. and Ss were instructed to describe how they attempted to form each association. These verbal reports were then classified according to the system developed by Martin, Boersma, \& Cox (1965).

In brief, Martin et al classified verbal repcorts 
TABLE I

Means and Variances of Associative Strategy Level Scores for the Four Lists

\begin{tabular}{|c|c|c|c|c|c|}
\hline \multicolumn{2}{|c|}{$M$ Value of S Term } & \multicolumn{2}{|c|}{$\begin{array}{lr}M \text { Value of } R \text { Term } \\
L=1.31 \quad H=7.48\end{array}$} & \multirow{2}{*}{$\frac{\text { Row Effects }}{33.0}$} & \multirow[t]{2}{*}{ S-Diff } \\
\hline \multirow{2}{*}{$L=1.30$} & $\bar{x}$ & 30.4 & 35.6 & & \\
\hline & $s^{2}$ & 140.7 & 120.4 & 130.6 & $\bar{X}=12.8$ \\
\hline \multirow{2}{*}{$H=7.60$} & $\bar{x}$ & 41.2 & 50.3 & 45.8 & $s^{2}=91.9$ \\
\hline & $s^{2}$ & 48.9 & 28.5 & 38.7 & \\
\hline \multirow[b]{2}{*}{$\begin{array}{l}\text { Column } \\
\text { Effects }\end{array}$} & $\bar{x}$ & 35.8 & 43.0 & & \\
\hline & $s^{2}$ & 94.8 & 74.5 & & \\
\hline \multirow{2}{*}{ R-Diff } & \multicolumn{3}{|c|}{$\overline{\mathrm{x}}=7.2$} & & \\
\hline & \multicolumn{3}{|c|}{$s^{2}=20.3$} & & \\
\hline
\end{tabular}

into seven categories: (1) No association, (2) Repetition, (3) Single letter cue, (4) Multiple letter cue, (5) Word formation, (6) Superordinate and (7) Syntactical. These categories are rank-ordered along an apparent continuum of cue complexity. A total strategy level score was obtained by summing strategy ratings over the eight pairs. Martin, Boersma and Cox obtained a statistically significant Spearman correlation coefficient $\left(r_{\mathrm{S}}=.62, \mathrm{df}=38, \mathrm{p}<.01\right)$ between total strategy scores and number of correct responses on ten trials. The reliability of the classification scheme was checked by having two judges independently rate verbal reports of $86 \mathrm{Ss}$ on an eight item L-L list. The Pearson correlation coefficient between the two judges' ratings of total strategy scores was .95 .

\section{Results and Diseussion}

Total number of correct responses in 10 trials was determined for each S. A 2 by 2 by 10 Lindquist (1953) Type III analysis revealed that all main and interaction effects were statistically significant $(p<.01)$. The order of difficulty with respect to treatment means was $\mathrm{L}-\mathrm{L}(36.4)<\mathrm{H}-\mathrm{L}(62.8)<\mathrm{L}-\mathrm{H}(68.7)$ $<\mathrm{H}-\mathrm{H}(73.4)$. The difference between main effects as a function of $\mathrm{M}$ as 15.55 for the stimulus, and 21.45 for the response. The greater effect of $M$ on the response side is similar to that obtained by Epstein (1963), and Cieutat, Stockwell \& Noble (1958). In short, although the experimental procedure attempted to control for equal response availability, a statistically significant response $M$ effect was obtained. Consequently, it appears that $M$ on the response side may be attributed to factors other than response availability.

A total strategy level score was obtained for each S by assigning to each pair the appropriate category level and then summing over pairs. For example, if the $\mathrm{S}$ reported using a Repetition strategy on three pairs ( 3 pairs learned by a 2 level strategy) and a Syntactical strategy on five pairs (5 pairs learned by a 7 level strategy) his total score would be 41 . The means and variance for the four groups are presented in Table 1. The rank order of mean strategy scores was $\mathrm{L}-\mathrm{L}<\mathrm{L}-\mathrm{H}<\mathrm{H}-\mathrm{L}<\mathrm{H}-\mathrm{H}$. A 2 by 2 factorial analysis was performed to assess the independent effects of stimulus and response $M$. The main effects were statistically significant beyond the .001 level and the interaction was negligible. For both stimulus and response effects, highest strategy scores were associated with H M items and greatest variance with LM items. The difference between main effects as a function of $M$ was $\mathbf{1 2 . 7 5}$ for the stimulus and 7.18 for the response. A post-hoc comparison using Scheffe's (1959) method of simultaneous confidence intervals revealed $(p<.05)$ that the $\mathrm{H}-\mathrm{H}$ group had significantly higher strategy level scores than the other three groups, and that the H-L group had significantly higher strategy level scores than the L-L group. In short, the data indicates that strategy level is more a function of stimulus $M$ than response $M$, that high $M$ items elicit higher level strategies than low $M$ items, and that variability in strategy scores increases as $M$ decreases.

To summarize, if the recognition procedure employed in this study produced equal response availability, then it can be argued that changes in response $M$ influence factors other than response availability. The findings concerning relative performance on the four lists and the greater influence of $M$ on the response side are consistent with previous studies. The associative strategy data, however, indicate that $\mathbf{M}$ also exerts an influence on the types of mediational cues employed by Ss during the learning task. More specifically, the analysis of strategy data revealed that $M$ has a greater effect on the stimulus than the response side. This finding provides some support to Underwood and Schulz's suggestion that stimulus $M$ exerts an influence during the associative learning stage. Moreover, it appears that the classification and analysis of the associative strategies may provide an alternative approach to the study of $\mathrm{M}$.

\section{References}

Cieutat, V. J., Stockwell, F. E., \& Noble, C. E. The interaction of ability and amount of practice with stimulus and response meaningfulness $\left(\mathrm{m}, \mathrm{m}^{\prime}\right)$ in paired-associate learning. J. exp. Psychol.,1958, 56, 193-202.

Epstein, W. The effect of stimulus and response meaningfulness when response availability is equated. J. verbal Learn. verbal Behav., 1963, 2, 242-249.

Lindquist, E. F. Design and analysis of experiments in psychology and education. Boston: Houghton Mifflin, 1953.

Martin, C. J., Boersma, F. J., \& Cox, D. L. Associative strategies in paired-associates learning. Paper read at meetings of Midwestern Psychological Association, 1965.

Noble, C. E. An analysis of meaning. Psychol. Rev., 1952, 59, 421-430.

Scheffe, H. The analysis of variance. New York: Wiley, 1959.

Underwood, B. J., \& Schulz, R. W. Meaningfulness and verbal learning. Philadelphia: Lippincott, 1960.

\section{Notes}

1. The project report herein was supported by a grant from the U. S. Department of Health, Education, and Welfare, Office of Education, Division of Handicapped Children and Youth.

2. The authors wish to thank Neal VanderVeen for his assistance in conducting this study. 